\title{
The Preferred Terminology Implemented by Psychedelic Users Existing on Online Platforms: A Cross-sectional Analysis
}

\author{
Ahmed Al-Imam ${ }^{1,2}$ \\ ${ }^{1}$ Department of Postgraduate Medicine, School of Life and Medical Sciences, University of Hertfordshire, United \\ Kingdom \\ ${ }^{2}$ Department of Anatomy and Cellular Biology, College of Medicine, University of Baghdad, Iraq \\ Correspondence: Dr Ahmed Al-Imam, House 18/5, Al-Akhtal Street, District 318, Al-Adhamyia, 10053, Baghdad, \\ Iraq. E-mail: tesla1452@gmail.com; a.m.al-imam@herts.ac.uk
}

Received: July 25, 2017 Accepted: August 17, 2017 Online Published: September 18, 2017

doi:10.5539/gjhs.v9n11p140 URL: https://doi.org/10.5539/gjhs.v9n11p140

\begin{abstract}
Background: The epidemiologic magnitude of the NPS (ab)use has been thoroughly explored and geographically mapped in the developed world. However, there are still untapped geographic locations primarily in the developing countries including the Middle East. Historically, mapping has been done via observational analytics, cross-sectionally and longitudinally, in addition to few experimental studies.
\end{abstract}

Materials and Methods: The study is cross-sectional; it will implement the internet snapshot technique, in addition to the application of thematic analysis and psychoanalysis of comments of NPS (ab)users on the online drug fora and social communication media. The data collected will be analysed for the purpose of concluding a statistical inference in relation to the terms most preferred by substance (ab)users towards hallucinogenic substances.

Results: The population was dominated by right-handed males; most of which were either heterosexual or bisexual. Psychedelics users have a preference for specific terms; psychedelic (73\%), entheogen (12\%), hallucinogen $(11 \%)$, spiritual aids $(3 \%)$, mysticomimetic $(1 \%)$, psychotomimetic $(<1 \%)$, medicines $(<1 \%)$, and trip $(<1 \%)$. Right-handed users who used the term psychedelic were a majority (53\%), while right-handed individuals using the terms entheogen and hallucinogen contributed to $8 \%$ for each.

Conclusion: This study is in line with other studies confirming the minute contribution of the Middle East to the global NPS phenomenon. Additional studies are mandatory for different populations including; students, academics and researchers, medical professionals, psychiatric patients, military and para-military organisations, delinquent and prisoners, and even terrorists.

Keywords: Substance-Related Disorders, Addictive Behavior, Novel Psychoactive Substances, NPS, Psychedelic Agents, Hallucinogens, observational study, terminology, cross-sectional studies, internet snapshot, epidemiology, public health, students, community medicine.

\section{Background}

Novel psychoactive substances (NPS), also known as designer drugs and research chemicals, have become a global phenomenon in the past two decades; its exponential growth is only paralleled by the logarithmic scale of development within the discipline of information and communication technologies, including the electronic commerce (e-commerce) on both divisions of the web (Brew, 2016; Krabseth et al., 2016; Orsolini et al., 2016). Several chemicals are categorised under NPS including the hallucinogenic agents (hallucinogens), also known as psychedelics and entheogens (Krebs \& Johansen, 2013; Schifano et al., 2016; Stafford, 2016).

Few attempts were prosecuted to study NPS and psychedelics in the developing world, and even a fewer attempts were committed for the region of the Middle East, Arabic countries, and the north of Africa (Al-Imam et al., 2016; Al-Imam, 2017a; Al-Imam, 2017b; Al-Imam et al., 2017; Al-Diwan et al., 2015; Al-Hemiary et al., 2014; Al-Hemiary et al., 2015; Al-Hemiary et al., 2016). However, the advent of numerous online platforms, including drug fora and virtual social communication media, enabled observational as well as experimental analyses to be carried out with ease allowing rigorous results (Hadgar, 2016; Joh et al., 2017; Moorhead et al., 2013). 
This study will rely on cross-sectional analysis of a population of psychedelic (ab)users existing on the online drug fora and social communication media (Erowid.org, 2017; Facebook, 2017). The study will be enacted in a population of (ab)users of psychedelic substances (hallucinogens) and NPS. The aim is to reach a conclusion in relation to the most frequently used terminology by psychedelic users. Hence, the cross-sectional analysis will explore the linguistic preferences of psychedelic (ab)users, and the potential correlation of those preferences with specific demographic parameters, including gender and patterns of lateralization of brain function.

\section{Materials and Methods}

This study has been ethically approved by the institutional review board (IRB) of the College of Medicine at the University of Baghdad (IRB meeting number 8 , on the $20^{\text {th }}$ of December 2016). An observational cross-sectional analysis was conducted on specific online platforms (Erowid.org, 2017; Facebook, 2017). The internet snapshots were taken from the $8^{\text {th }}$ to the $25^{\text {th }}$ of February 2017; the purpose was to infer the most commonly used terms (linguistic preferences) for psychedelics. A number of terms have been observed during an initial screening; these terms have been tabulated for each psychedelic users, creating a database of 239 entries $(n=239)$. Those individuals were representative of the studied populations due to the following; firstly, each of the online platforms was private (not public) and accessible only by people with high interest in using hallucinogenic substances, secondly, prior to joining any of the online platforms, the administrators implemented a quiz of relevance to the utilization and subjective experiences of those substances, and thirdly the individuals for whom commentaries were analyzed were followed-up on those platforms to fully confirm their attitude and tendencies to (ab)user psychedelic substances; these were confirmed via; self-declaration of (ab)use from published posts, and interactions with other members within the same platform.

Furthermore, threads of commentaries with terms of relevance to psychedelics were scanned by accessing the profile page of each contributing users for four main parameters including age, gender, handedness, and sexual orientation. Handedness can be potentially correlated either with certain substance (ab)use and with the linguistic preference towards terms; the same concept applies to sexual orientation and gender. A number of hypotheses have been proposed of the potential correlation of handedness or sexual orientation with the tendency to (ab)use psychedelics.

Data will be analysed via descriptive and inferential statistics at an alpha value of 0.05 and a confidence interval of 95\% (95\% CI). Implemented inferential statistics will include; Student's t-test, and nonparametric inferential statistics particularly the Mann-Whitney U test and the Kruskal-Wallis $H$ test. Statistical analyses will attempt to extrapolate significant differences in relation to; gender versus age of psychedelic users (1), handedness versus age (2), age versus the most frequently used terms (3), handedness versus the most commonly used terms (4), and gender versus the most commonly used terms (5). The outcome can be considered by future studies to be incorporated as a representative of demographic parameters in psychedelic users. The level-of-evidence of this study is level-2b in accordance with the classification scheme imposed by the Oxford Center for Evidence-Based Medicine (CEBM) (University of Oxford, 2009).

\section{Results and Discussion}

The discovered terms during the initial screening were; Psychedelic, Entheogen (generating the divine within), Hallucinogen, mysticomimetic (mimicking mystical state), Oneirogen (creating dreams), Psychotomimetic (mimicking psychosis), Psychotogen (Producing psychosis), Spiritual Aids, and trip. Accordingly, the most frequently used terms for each individual were tabulated together in addition to demographics; age, gender, handedness, and sexual orientation (whenever declared) in a database of 239 entries (Figure 1). The age was ranging from 14 to 70 years; median age was 25 , and the mean age was $30.7(+/-14.4)$ years, while the most common age (mode) was 22 years. Exceptional age (statistical outliers) included those aged 60 years and above; unique age groups for psychedelic users should be investigated in future studies. Males predominated the studied population at $74 \%$, the females represented $24 \%$, while the rest of the population (2\%) were identified as transgender individuals (Figure 2). The majority were right-handed (92.1\%), while left-handed users were the remaining population (7.9\%), and no ambidextrous individuals were detected. The handedness of this community of psychedelic e-users is in harmony with that of the standard healthy population (Corballis, 2014; Costanzo et al., 2015). Apparently, there are no indicators for a particular correlation between the patterns of cerebral dominance (manifested by handedness) and the tendency to (ab)use psychedelic substances. Similarly, most were heterosexual (85.5\%), bisexual individuals were unexpectedly high (13.9\%), while gay and lesbians (homosexuals) represented a minority $(0.6 \%)$. Accordingly, it is possible that sexual orientation to be correlated with the individual's tendency to (ab)use hallucinogenic substances or other types of psychoactive substances including novel ones; larger samples are required to confirm this assumption. 


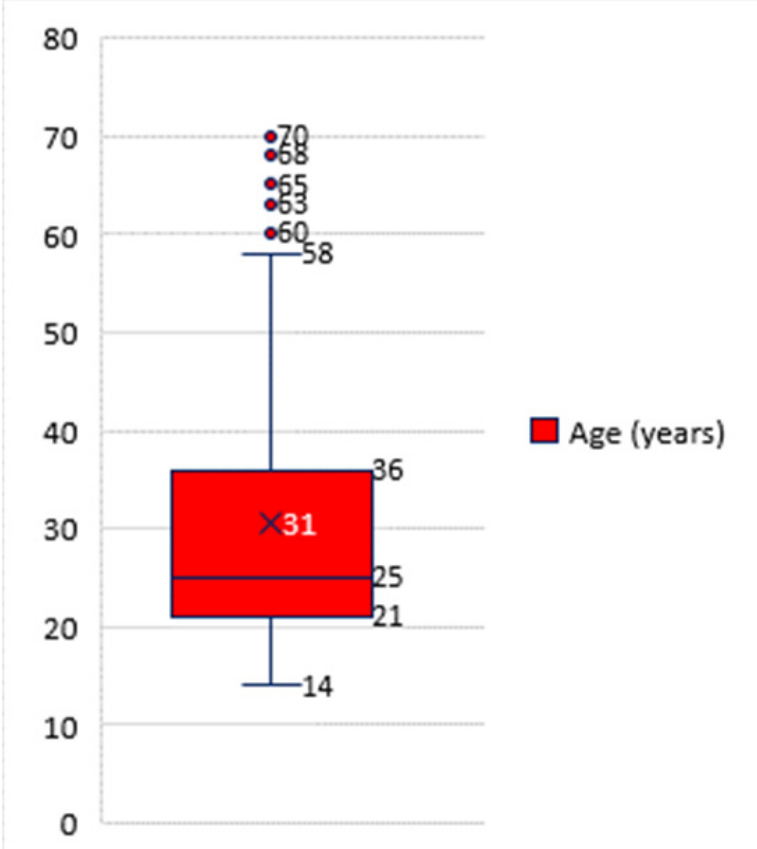

Figure 1. Age of Psychedelic (Ab)users: Boxplot Presentation

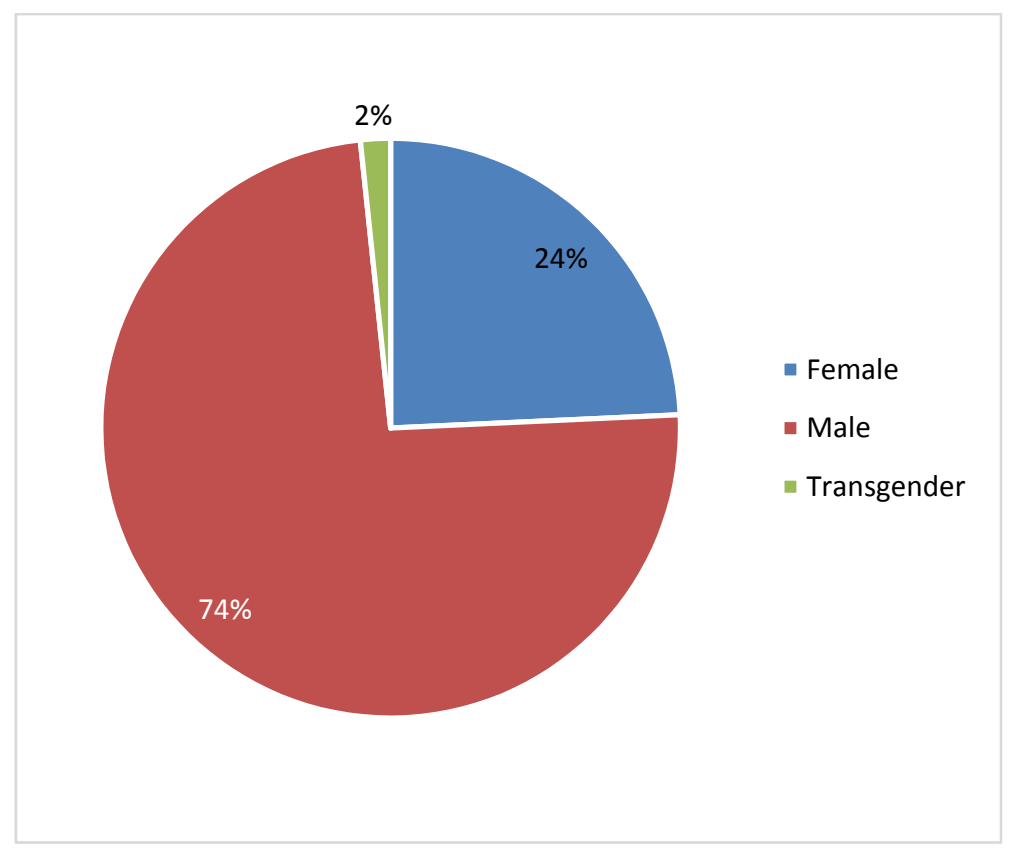

Figure 2. Gender of Psychedelic (Ab)users

The majority of males and females were right handed (Figure 3), left-handed men and women represented $5 \%$ and $2 \%$ respectively, while transgender individuals were exclusively right-handed. The most frequently used terms (Figure 4) were; psychedelic (73\%), entheogen (12\%), hallucinogen (11\%), spiritual aids (3\%), mysticomimetic $(1 \%)$, psychotomimetic $(<1 \%)$, medicines $(<1 \%)$, and trip $(<1 \%)$. Further descriptive analysis (Figure 5$)$ showed that right-handed individuals who used the term psychedelic were a majority (53\%), while right-handed individuals using the terms entheogen and hallucinogen contributed to $8 \%$ for each. 


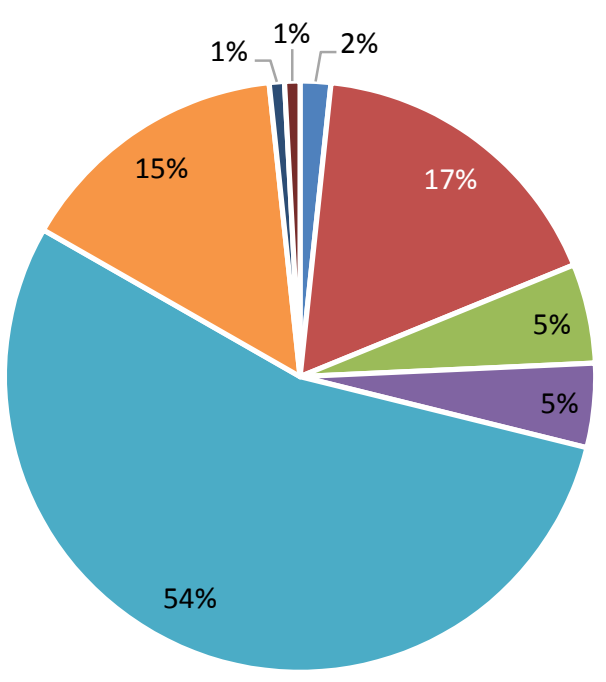

- Female Left-handed

- Female Right-handed

- Female (blank)

- Male Left-handed

- Male Right-handed

- Male (blank)

- Transgender Right-handed

- Transgender (blank)

Figure 3. Handedness versus Gender in Psychedelic (Ab)users

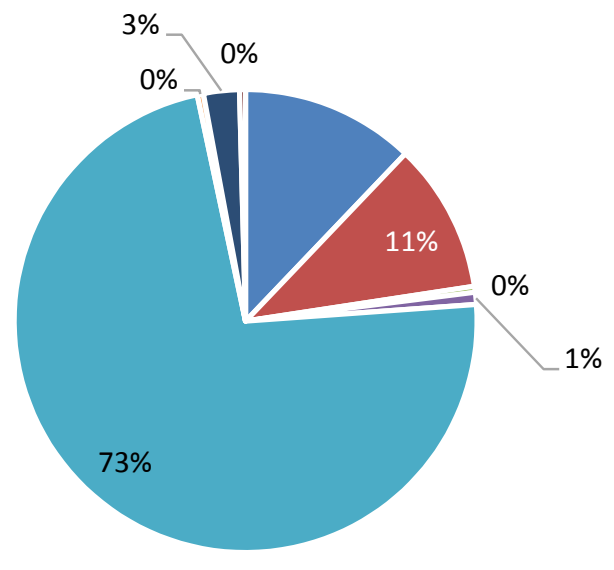

- Entheogen

- Hallucinogen

- Medicines

- Mysticomimetic

- Psychedelic

- Psychotomimetic

- Spiritual Aids

- Trip

Figure 4. The Most Frequently Used Terms for Psychedelics 


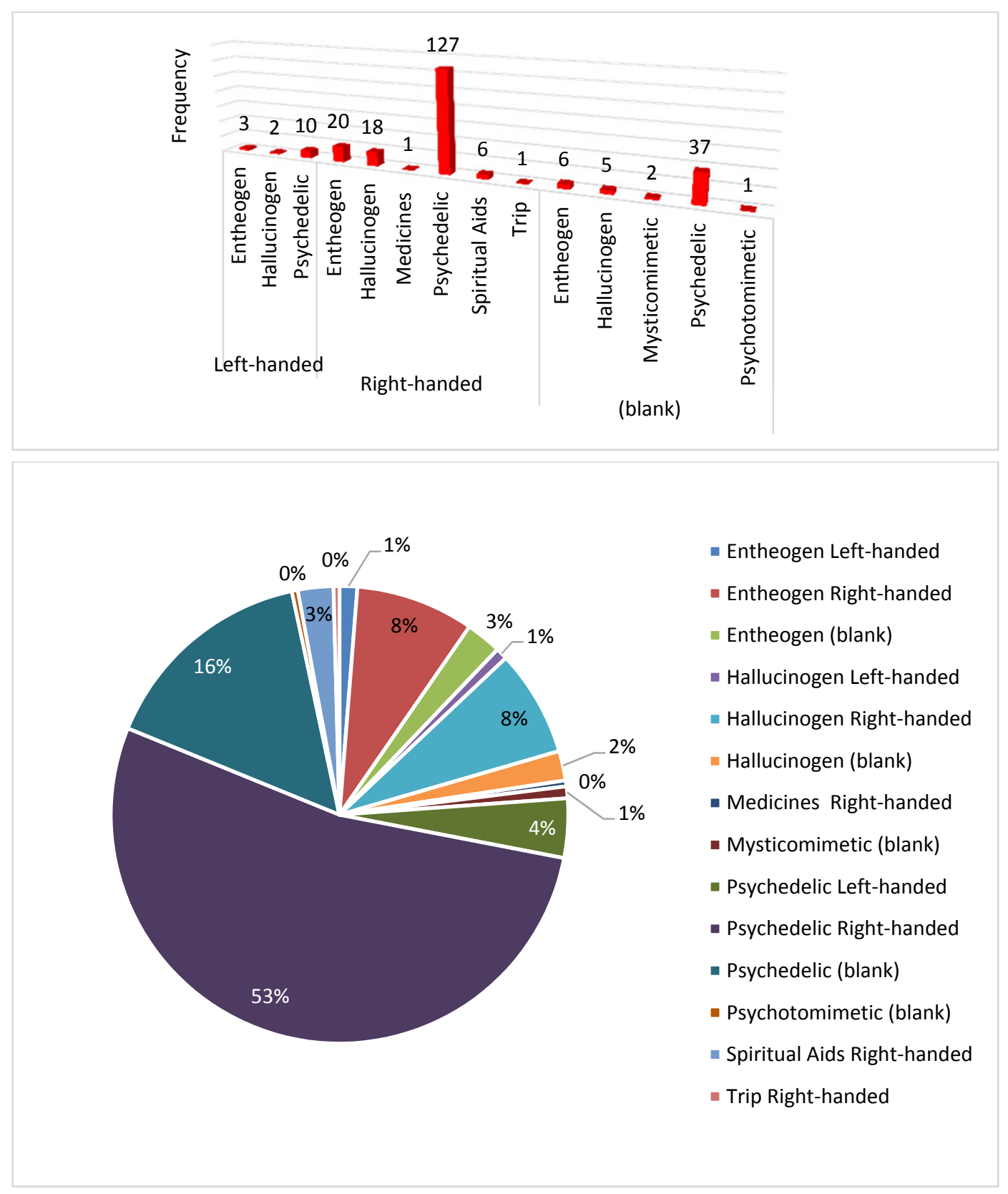

Figure 5. Descriptive Analyses: Handedness versus Terms

The analysis via Student's t-test (unpaired) confirmed the absence of any statistically significant difference in age between males versus females $(30.9+/-14.4$ versus $30.6+/-14.7, p$-value $=0.440)$. However, there was a significant difference in relation to handedness; right-handed psychedelic users were significantly older than left-handed $(31.2+/-14.8$ versus $25.8+/-7.7, \mathrm{p}=0.013)$. The top three used terms were; psychedelic (rank $\left.1^{\text {st }}\right)$, entheogen $\left(2^{\text {nd }}\right)$, and hallucinogen $\left(3^{\text {rd }}\right)$. These were further analysed for differences in relation to age (Table 1); Individuals who used the term psychedelic were significantly younger than those who used the term hallucinogen $(29.1+/-14.5$ versus $35.8+/-15.2$, $p$-value $=0.025)$, the same individuals were also significantly younger than the ones who frequently used the term entheogen $(29.1+/-14.5$ versus $33.2+/-11.5, p=0.049)$. 
Table 1. Descriptive and Inferential Statistics: Terms versus Age.

\begin{tabular}{lcc}
\hline & Age (Mean) & St. Dev. \\
\hline Psychedelic & 29.14 & 14.54 \\
Hallucinogen & 35.76 & 15.20 \\
Entheogen & 33.21 & 11.49 \\
\hline & & \\
\hline & & $p$-value \\
\hline Psychedelic vs Hallucinogen & & 0.025 \\
Psychedelic vs Entheogen & & 0.049 \\
Psychedelic vs Entheogen & & 0.248 \\
\hline
\end{tabular}

There was also a significant difference (Table 2) in age between right and left-handed individuals who preferred using the term psychedelics; right-handed individuals were significantly older $(29.9+/-15.5$ versus $24+/-5.3$, $p$-value $=0.006$ ), while there was no significant difference in age in between right and left-handed individuals in relation to the other two frequently used terms; hallucinogen $(\mathrm{p}=0.333)$ and entheogen $(\mathrm{p}=0.312)$. Inferences were different when it came to the analysis of terms versus gender and handedness (Table 3); right-handed females who used the term entheogen were significantly older than right-handed males who used the same term $(41.1+/-10.2$ versus $30.4+/-10.2, \mathrm{p}=0.012$ ). On the other hand, there were no differences in age between right-handed males and right-handed females who used the terms; hallucinogen $(\mathrm{p}=0.236)$ and psychedelic $(\mathrm{p}=0.119)$.

Table 2. Descriptive and Inferential Statistics: Terms versus Age and Handedness.

\begin{tabular}{|c|c|c|c|c|}
\hline & \multicolumn{2}{|c|}{ Age (Mean) } & \multicolumn{2}{|c|}{ St. Deviation } \\
\hline & Rt. Handed & Lt. Handed & Rt. Handed & Lt. Handed \\
\hline Entheogen & 34.10 & 30.33 & 12.10 & 13.05 \\
\hline Hallucinogen & 32.61 & 28.00 & 11.82 & 11.31 \\
\hline \multirow[t]{3}{*}{ Psychedelic } & 29.94 & 24.00 & 15.51 & 5.29 \\
\hline & & \multicolumn{3}{|c|}{ Age vs Handedness ( $p$-value) } \\
\hline & & Entheogen & & 312 \\
\hline \multicolumn{2}{|c|}{ Non-parametric } & Hallucinogen & & 333 \\
\hline & & Psychedelic & & 006 \\
\hline
\end{tabular}

Table 3. Descriptive and Inferential Statistics: Terms versus Gender and Handedness.

\begin{tabular}{lcccc}
\hline & \multicolumn{2}{c}{ Age (Mean) } & \multicolumn{2}{c}{ St. Deviation } \\
\cline { 2 - 5 } & Male & Female & Male & Female \\
\hline Entheogen & 30.40 & 41.13 & 10.89 & 10.20 \\
Hallucinogen & 37.32 & 30.83 & 13.92 & 19.30 \\
Psychedelic & 29.98 & 27.05 & 15.03 & 13.03 \\
\hline \multicolumn{5}{c}{ Age vs Gender (p-value) } \\
\hline t-test & Hallucinogen & \multicolumn{3}{c}{0.012} \\
& Psychedelic & 0.236 \\
& & & 0.119 \\
\hline
\end{tabular}




\section{Conclusions}

The internet snapshots have revealed that in a population of psychedelic (ab)users, there was a preference towards specific terms for hallucinogenic substances; the top utilized terms were psychedelic, entheogen, and hallucinogen. There was also some significant difference in between the psychedelic (ab)users based on; age, gender, and patterns of handedness. The vast majority of (ab)users were; young, predominantly of males, and from the western developed world. Future studies should direct a particular attention towards the developing countries, and implement studies in a heterogeneity of populations including; students, researchers, medical professionals, psychiatric patients, and criminals

\section{Competing Interests Statement}

The authors have no conflict of interest to be declared.

\section{Source of Funding}

This study was entirely self-funded.

\section{References}

Al-Diwan, J., Al-Hemiary, N., \& Hashim, M. (2015). Alcohol and Drug Abuse in Post-conflict Iraq. European Psychiatry, 30, 1394. https://doi.org/10.1016/S0924-9338(15)31080-4

Al-Hemiary, N. J., Hashim, M., Al-Diwan, J., \& Abdulrazzak, E. (2010). Alcohol and drug abuse in post-conflict Iraq. Unpublished manuscript. Baghdad University, Iraq.

Al-Hemiary, N. J., Hashim, F. M., \& Al-Shawi, C. A. (2016). Effect of post-traumatic stress disorder on school achievement among secondary school students in Baghdad, Iraq. J Fac Med Baghdad, 58(2).

Al - Hemiery, N., Dabbagh, R., Hashim, M. T., Al - Hasnawi, S., Abutiheen, A., Abdulghani, E. A., ... \& Brecht, M. L. (2017). Self - reported substance use in Iraq: findings from the Iraqi National Household. Survey of Alcohol and Drug Use, 2014. https://doi.org/10.1111/add.13800

Al-Imam, A. (2017a). Could Hallucinogens Induce Permanent Pupillary Changes in (Ab) users? A Case Report from New Zealand. Case Reports in Neurological Medicine, 2017. https://doi.org/10.1155/2017/2503762

Al-Imam, A. (2017b). The relation between cerebral dominance and visual analytic skills in Iraqi Medical students, a cross sectional analysis. Journal of the Anatomical Society of India, 66(1), 42-43. https://doi.org/10.1016/j.jasi.2017.08.136

AL-Imam, A., Santacroce, R., Roman - Urrestarazu, A., Chilcott, R., Bersani, G., Martinotti, G., \& Corazza, O. (2017). Captagon: use and trade in the Middle East. Human Psychopharmacology: Clinical and Experimental, $32(3)$.

Al-Imam, A., Simonato, A. P., \& Corazza, O. (2016). Haloperidol, an old antipsychotic with potential use by NPS users in Iraq. Research and Advances in Psychiatry, 3(3), 81-84. Retrieved from https://www.rapjournal.eu/materiale_cic/948_3_3/8031_haloperidol/article.htm

Brew, I. (2016). Novel psychoactive substances. The British Journal of General Practice, 66(644), 125. https://doi.org/10.3399/bjgp16X684253

Corballis, M. C. (2014). Left brain, right brain: facts and fantasies. PLoS biology, 12(1), e1001767. https://doi.org/10.1371/journal.pbio.1001767

Costanzo, E. Y., Villarreal, M., Drucaroff, L. J., Ortiz-Villafa-e, M., Castro, M. N., Goldschmidt, M., ... Camprodon, J. A. (2015). Hemispheric specialization in affective responses, cerebral dominance for language, and handedness: lateralization of emotion, language, and dexterity. Behavioural brain research, 288, 11-19. https://doi.org/10.1016/j.bbr.2015.04.006

Erowid.org. Retrieved 16 March, 2017, from Erowid. https://www.erowid.org/

Facebook. Retrieved 16 March, 2017, from Facebook. https://www.facebook.com/

Facebook. Magic Mushroom (Psilocybin). Retrieved 16 March, 2017, from https://www.facebook.com/groups/1546595612323918/

Facebook. Psychedelic Experience. Retrieved 16 March, 2017, from https://www.facebook.com/groups/815158201837615/

Facebook. Psychedelic Heaven. Retrieved 16 March, 2017, from https://www.facebook.com/groups/Psychedelic.Heaven/ 
Facebook. Psychedelics \& Philosophy 2. Retrieved 16 March, 2017, from https:/www.facebook.com/groups/1233956900000615/permalink/1315808575148780/?comment_id=13159533 78467633 $\neg$ if_t $=$ group_comment $\neg$ if_id=148742705280730

Facebook. The Adult Psychedelic Sweet Shop. Retrieved 16 March, 2017, from https:/www.facebook.com/groups/763405830462403/

Facebook. The Terance McKenna Experience. Retrieved 16 March, 2017, from https://www.facebook.com/groups/terencemckenna/

Krabseth, H. M., Tuv, S. S., Strand, M. C., Karinen, R. A., Wiik, E., Vevelstad, M. S., ... \& Vindenes, V. (2016). Novel psychoactive substances. Tidsskrift for den Norske laegeforening: tidsskrift for praktisk medicin, ny raekke, 136(8), 714-717. https://doi.org/10.4045/tidsskr.15.1278

Krebs, T. S., \& Johansen, P. Ø. (2013). Psychedelics and mental health: A population study. PloS one, 8(8), p.e63972. https://doi.org/10.1371/journal.pone.0063972

Orsolini, L., Papanti, D., Vecchiotti, R., Valchera, A., Corkery, J., \& Schifano, F. (2016). Novel psychoactive substances. European Psychiatry, 33, S59-S60. https://doi.org/10.1016/j.eurpsy.2016.01.945

Schifano, F., Orsolini, L., Duccio Papanti, G., \& Corkery, J. M. (2015). Novel psychoactive substances of interest for psychiatry. World Psychiatry, 14(1), 15-26. https://doi.org/10.1002/wps.20174

Stafford, P. (2013). Psychedelics encyclopedia. Ronin Publishing.

University of Oxford. Center for Evidence Based Medicine. Retrieved 16 March, 2017, from http://www.cebm.net/.2009

\section{Copyrights}

Copyright for this article is retained by the author(s), with first publication rights granted to the journal.

This is an open-access article distributed under the terms and conditions of the Creative Commons Attribution license (http://creativecommons.org/licenses/by/4.0/). 